\title{
Insomnia: A Foremost Deprived Factor; Cross Sectional Study
}

Safila Naveed ${ }^{1 *}$, Fatima Qamar', Sidrah Khan ${ }^{1}$, Syeda Sarah Abbas ${ }^{1,2}$, Syed Hameez Jawed ${ }^{2}$, Summaya Naz ${ }^{1}$, Usra Kausar ${ }^{1}$ and Jaweriya Abbas $^{1}$

${ }^{1}$ Jinnah University for Women, Karachi, Pakistan

${ }^{2}$ Department of Pharmaceutics, University of Karachi, Pakistan

\begin{abstract}
Insufficient sleep could be a public health epidemic becomes one among the foremost current health considerations within the population and in clinical apply. Clinicians are also unwilling to handle it due to its several probable causes, unusualness action and considerations regarding medical specialty treatments. Insufficient sleep is said when you regularly find it hard to fall asleep or stay asleep. It has many patterns. You will have hassle attending to sleep at first. Or possibly if you'll be able to go to sleep, you would possibly not to keep asleep for as long as you'd like. Furthermore you will wake throughout the night and not be ready to return to sleep for a protracted time. In this article we did a survey study and analyze the sleep deprived persons and their impact on their general health. Here the result shown that the sleep deprived can lead to many complications.
\end{abstract}

Keywords: Insufficient sleep; Memory; Healthy sleep; Depression; Sleep deprived

\section{Introduction}

\section{Objective of the study}

It has many patterns. You will have hassle attending to sleep at first. Or possibly if you'll be able to go to sleep, you would possibly not to keep asleep for as long as you'd like. Furthermore you will wake throughout the night and not be ready to return to sleep for a protracted time.

Many of us have two of the on top of issues, or may be all three. Due to of these, you would possibly feel tired during the day. Clinicians should recognize the cause for insufficient sleep because of its effects on operate and health. Behavioral treatments should to be used when possible. Hypnotic/sedative medications are typically as well efficacious however should be carefully monitored for adverse effects.

The main objective behind this study is to analyze the sleep pattern and their influence on general health among different people with different occupation, gender and age.

Just as vital are the positive benefits that obtaining good sleep provides. Sound sleep helps boosts the immune system, repairs the body systems improve alertness, helps in learning, concentration, driver safety, energy, focus, creativity, judgment, and dealing memory [1]. The problem is that our culture once looked upon sleep as a waste of time; however it's currently changing into clear just how essential sleep is to living well, blissful and productive lives [2]. Throughout deep, restorative sleep is once the body heals, produces vital hormones, and solidifies memories. With such a big amount of individuals experiencing such a big amount of completely different sleeping issues, it can be tricky to know exactly what qualifies as "healthy sleep." "Healthy sleep leaves the individual 'rested' and not feeling drowsy through the day," Ayers said. "Normal sleep includes deep sleep, Rapid Eye Movement (REM) and light sleep." [3] Sleep is increasingly recognized as important to public health, with sleep shortage linked to motor vehicle crashes, industrial disasters, and working errors [4]. Unintentionally falling asleep, nodding off while driving, machine or instrument handling and having issue activity daily tasks because of sleepiness all may contribute to these dangerous outcomes [5]. Individual suffering sleep insufficiency are also more likely to suffer from chronic diseases such as increased blood pressure, depression, and obesity, as well as from cancer, multiplied mortality, and reduced quality of life and productivity. Sleep insufficiency may be caused by large scale social group factors such as day-and-night access to technology and work schedules; however sleep disorders such as insomnia or obstructive sleep apnea also play an important role. You climb into bed tired and exhausted. But the minute you're wide awake, your anxiety builds. Table 1 shows average time of sleep per day according to age $[6,7]$.

\section{Symptoms}

The most common symptoms are: difficulty falling asleep, waking up through the night, waking up early in the morning, Feeling irritable and tired and finding it troublesome to function throughout the day [8].

\section{Risk factors}

It affects about two percent of individuals who go to a sleep center

\begin{tabular}{|c|c|}
\hline Age & $\begin{array}{c}\text { Sleep Needed } \\
\text { average per day }\end{array}$ \\
\hline Infants & Up to 18 hours \\
\hline $1-12$ months & $14-18$ hours \\
\hline $1-3$ years & $12-15$ hours \\
\hline $3-5$ years & $11-13$ hours \\
\hline $5-12$ years & $9-11$ hours \\
\hline Teens & $9-10$ hours \\
\hline Adults & $7-8$ hours \\
\hline Pregnant women & Varies \\
\hline
\end{tabular}

Table 1: Average time of sleep per day according to age.

*Corresponding author: Safila Naveed, Faculty of Pharmacy, Jinnah University for Women, Karachi, Pakistan, Tel: 0092-03002621917; E-mail: safila117@yahoo.com

Received October 27, 2015; Accepted December 02, 2015; Published December 09,2015

Citation: Naveed S, Qamar F, Khan S, Abbas SS, Jawed SH, et al. (2016) Insomnia: A Foremost Deprived Factor; Cross Sectional Study. J Bioequiv Availab 8: 033-036. doi:10.4172/jbb.1000263

Copyright: @ 2016 Naveed S, et al. This is an open-access article distributed unde the terms of the Creative Commons Attribution License, which permits unrestricted use, distribution, and reproduction in any medium, provided the original author and source are credited. 
for facilitate. It needs to start in adults who are in their mid-to-late 30 s. It usually goes unseen until they reach 40 s. It affects more than men as compared to women $[9,10]$.

\section{Diagnosis}

You should see a sleep specialist for a review of all your symptoms. He or she can detect alternative sleep disorders that will be the reason for your temporary state. Sleepiness can be a result of many other sleep disorders [11]. These comprise the following: Environmental sleep disorder, Psycho physiological insomnia, Obstructive sleep apnea, Central sleep apnea, Narcolepsy, Idiopathic hypersomnia, Short sleeper, Shift work disorder, Delayed sleep phase disorder, Periodic limb movement disorder [12]. With this recent awareness of the condition, and an increasing demand for solutions, an excess of digital devices and apps have emerged to measure how well people are sleeping. Some of these are more precise than others and they can set up a baseline and get us thinking about sleep and tracking progress. The doctor will desire to know your medical history. You may also need to keep a sleep diary for several weeks. This will show your sleep and wakeup time. An overnight sleep study may be performed. This is called a polysomnogram. It records your brain waves, Cardiac rhythm abnormalities, leg movements, body position during sleep, this show if there are other sleep disorders that are causing your sleepiness [13]. You may also stay to take a nap study after that day. This is called a Multiple Sleep Latency Test. It records how fast you fall asleep throughout the day. It additionally shows what kind of sleep you have got when you take a nap. Other lab tests may also be additionally be required. Other sleep disorders should first be ruled out as the cause of your sleepiness. Insufficient sleep syndrome is definitely treated once it's found to be the matter. You may merely need to begin sleeping for an extended amount of your time every night. This should end the symptoms [14].

\section{Sleep hygiene tips}

The promotion of fine sleep habits and regular sleep is known as sleep hygiene. The following sleep hygiene tips may be used to improve sleep; go to bed at constant time each night and rise at constant time every morning, avoid massive meals before bedtime, avoid caffeine at bedtime, avoid alcohol at bedtime, avoid nicotine [15]

\section{The do's and don'ts to a better night's sleep}

Millions of individuals are all too familiar with the suffering of a sleepless night. However whereas several of us might not suppose a lot of regarding landscapist our low within the morning and troubled through the day, sleep deprivation are often a heavy downside and a few of our daily behaviors will really build matters worse [16]. The Centers for Disease Control and Prevention (CDC) describes sleep deprivation as a "public health epidemic." Your body naturally produces a hormone called melatonin to assist management the temporal arrangement of waking and sleeping. Melatonin levels spike up at night, sign that it's time to go to sleep [17].

Dr. Michael J. Breus, a clinical psychologist and expert in sleep medicine, says your attitude shouldn't simply be regarding the amount of sleep you get-it should even be concerning quality. To exploit your sleep quality, it's best to avoid activities that might disrupt your body's production of melatonin or cause you to skip certain stages of sleep [18].

\section{What you're doing wrong}

Light is one major issue which will disrupt the sleep cycle. Several studies have shown that light and notably blue light will suppress the body's production of melatonin. Unfortunately, several electronic devices with backlit screens, like cell phones, produce blue light. This means checking your text messages before bed will interfere along with your ability to urge to sleep $[19,20]$.

\section{How to sleep better}

Some doctors recommend a sleep aid for the chronically sleep deprived. Melatonin, is a hormone that also available as an over-thecounter sleep aid, but it's important to use it properly. Barone cautions that many people create the error of taking too much melatonin, which he says can make you feel dazed or "hungover" the after that day. $\mathrm{He}$ recommends a dose of 1 to $3 \mathrm{mg}$ used. Breus is even more cautious-he says 0.5 to 1 milligram should be enough $[21,22]$.

Naps can also be a useful tool. If you're awakening tired, Breus recommends napping early in the day around 1 p.m. or so for about 90 minutes if possible, even though he says a 20-25 minute catnap can also be helpful. Napping too long or too late within the day will create it tougher to fall asleep at night; therefore keeping naps short and early is best. Education is essential to helping people to get an improved night's sleep. Considerate the sleep cycle and also the factors which will influence it is the best way to begin creating selection that improve instead of sabotage-your quality of sleep, resulting in a healthier and better-rested you. Sleep deprivation can noticeably affect people's performance, as well as their ability to assume clearly, react quickly, and form memories. Sleep deprivation additionally affects mood, resulting in irritability; issues with relationships, particularly for children and teenagers; and depression. Sleep deprivation may increase anxiety [23].

\section{Methodology}

We have conducted a cross sectional survey of 120 individuals belonging to different demographics including students; education (teachers), medical; officers, and rests are random people. 120 people were inquired about if the quality of sleep affects their day function (i.e. fatigue, mood, irritability).

\section{Result and Discussion}

Out of 120 people, $18 \%$ says that the quality of sleep does not affect their day function (i.e. fatigue, mood, irritability). $34 \%$ says that the quality of sleep slightly affects their day function (i.e. fatigue, mood, irritability). $34 \%$ says that the quality of sleep moderately affects their day function (i.e. fatigue, mood, irritability). $13 \%$ says that the quality of sleep severely affects their day function (i.e. fatigue, mood, irritability). Students were asked about if they were sleep deprived as a student as shown in Figure 1. Out of 120 people 87 are students; $71 \%$ says that they're sleep deprived as a student. $29 \%$ says that they're not sleep deprived as a student as shown in Figure 2. Out of 120 people; $20 \%$ says that on a day when they didn't get sufficient sleep that night before, they don't feel harder to stay awake/ focused during their classes or at work. $30 \%$ says that on a day when they didn't get sufficient sleep that night before, they feel slightly harder to stay awake/ focused during their classes or at work. $28 \%$ says that on a day when they didn't get sufficient sleep that night before, they feel moderately harder to stay awake/ focused during their classes or at work. $22 \%$ says that on a day when they didn't get sufficient sleep that night before, they feel severely harder to stay awake/ focused during their classes or at work (Figure 3). People were inquired about how many hours of sleep do they feel to need at night to function well the next day? $52 \%$ says that they need 7-8 hours of sleep in a night to function well the next day. $31 \%$ says 
Citation: Naveed S, Qamar F, Khan S, Abbas SS, Jawed SH, et al. (2016) Insomnia: A Foremost Deprived Factor; Cross Sectional Study. J Bioequiv Availab 8: 033-036. doi:10.4172/jbb.1000263

that they need 8-9 hours of sleep in a night to function well the next day. $12 \%$ says that they need $9-10$ hours of sleep in a night to function well the next day. $4 \%$ says that they need $<8$ hours of sleep in a night to function well the next day (Figure 4).

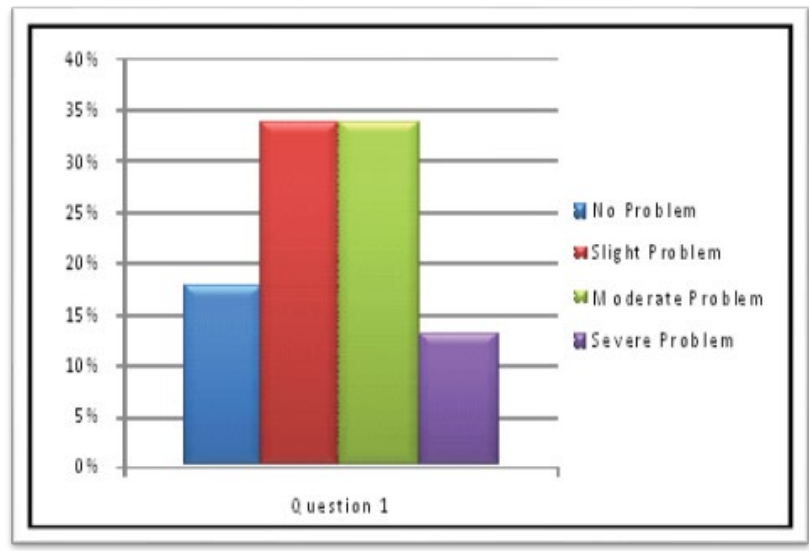

Figure 1: How much does the quality of sleep affects your day function (i.e. fatigue, mood, irritability)?

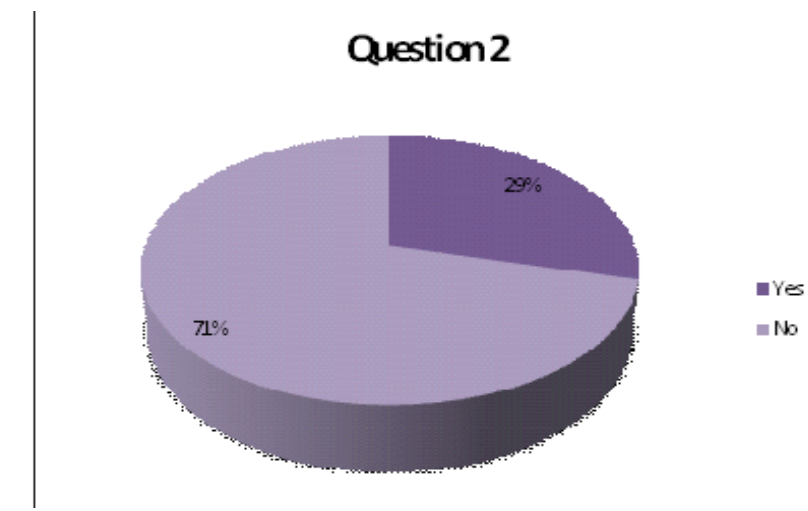

Figure 2: Do you feel that you're sleep deprived as a student?

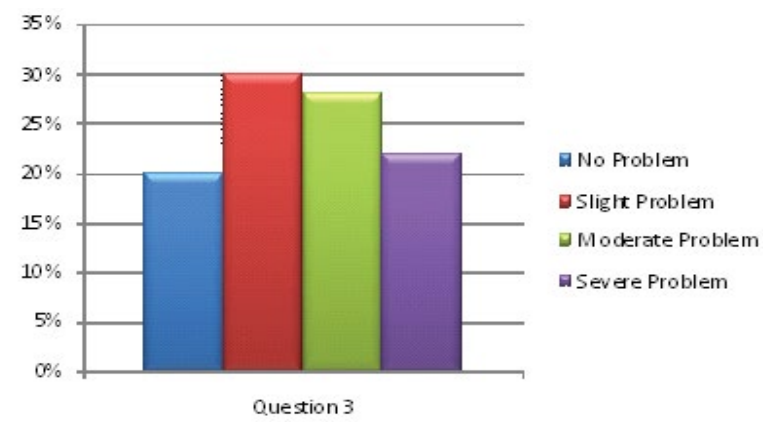

Figure 3: On a day where you did not get sufficient sleep the night before, do you find it harder to stay awake /focused during your classes or at work?

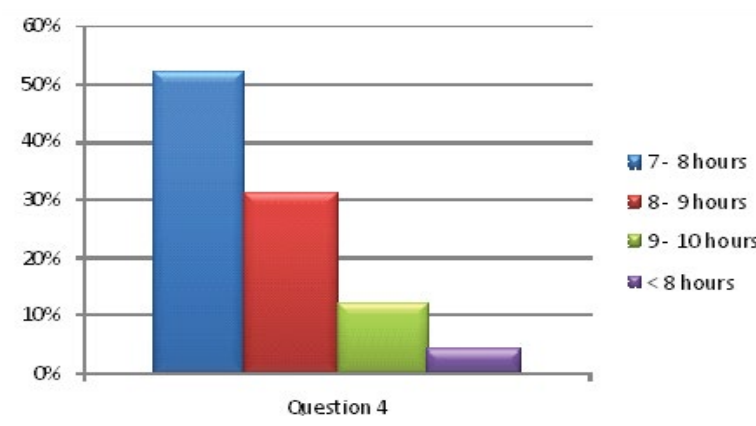

Figure 4: How many hours of sleep do you feel you need at night to function well for the next day?

In this survey based study and under the light of different researches and studies on sleep insufficiency it is foremost necessary for an individual to complete their sleep requirement up to at least 8 hours or they can takes certain naps meanwhile to overcome their exertion and irritation. We have done these types of studies before in order to generate awareness in the society and bring better health care [24-29].

\section{References}

1. Morin CM, Hauri PJ, Espie CA, Spielman AJ, Buysse DJ, et al. (1999) Nonpharmacologic treatment of chronic insomnia. An American Academy of Sleep Medicine review. Sleep 22: 1134-1156.

2. Ohayon MM (2002) Epidemiology of insomnia: what we know and what we stil need to learn. Sleep Med Rev 6: 97-111.

3. Foley DJ, Monjan A, Simonsick EM, Wallace RB, Blazer DG (1999) Incidence and remission of insomnia among elderly adults: an epidemiologic study of 6,800 persons over three years. Sleep 22 Suppl 2: S366-372.

4. Buysse DJ, Ancoli-Israel S, Edinger JD, Lichstein KL, Morin CM (2006) Recommendations for a standard research assessment of insomnia. Sleep 29 1153-1173.

5. Ancoli-Israel S, Roth T (1999) Characteristics of insomnia in the United States: results of the 1991 National Sleep Foundation Survey. I. Sleep 22 Suppl 2 S347-353.

6. Terman LM, Hocking A (1913) The sleep of school children, its distribution according to age, and its relation to physical and mental efficiency. Journal of Educational Psychology 4: 138-147.

7. Wolfson AR, Carskadon MA (1998) Sleep schedules and daytime functioning in adolescents. Child Dev 69: 875-887.

8. Roberts RE, Lee ES, Hemandez M, Solari AC (2004) Symptoms of insomnia among adolescents in the lower Rio Grande Valley of Texas. Sleep 27: 751-760.

9. Bastien $\mathrm{CH}$, Vallières A, Morin $\mathrm{CM}$ (2001) Validation of the Insomnia Severity Index as an outcome measure for insomnia research. Sleep Med 2: 297-307.

10. Spielman AJ, Saskin P, Thorpy MJ (1987) Treatment of chronic insomnia by restriction of time in bed. Sleep 10: 45-56.

11. Zammit GK, Weiner J, Damato N, Sillup GP, McMillan CA (1999) Quality of life in people with insomnia. Sleep 22 Suppl 2: S379-385.

12. Roth T, Ancoli-Israel S (1999) Daytime consequences and correlates of insomnia in the United States: results of the 1991 National Sleep Foundation Survey. II. Sleep 22 Suppl 2: S354-358.

13. Walsh JK, Engelhardt CL (1999) The direct economic costs of insomnia in the United States for 1995. See comment in PubMed Commons below Sleep 22 Suppl 2: S386-393.

14. Stoller MK (1994) Economic effects of insomnia. Clin Ther 16: 873-897.

15. Tochikubo O, Ikeda A, Miyajima E, Ishii M (1996) Effects of insufficient sleep 
Citation: Naveed S, Qamar F, Khan S, Abbas SS, Jawed SH, et al. (2016) Insomnia: A Foremost Deprived Factor; Cross Sectional Study. J Bioequiv Availab 8: 033-036. doi:10.4172/jbb.1000263

on blood pressure monitored by a new multibiomedical recorder. Hypertension 27: $1318-1324$

16. Hublin C, Kaprio J, Partinen M, Koskenvuo M (2001) Insufficient sleep--a population-based study in adults. Sleep 24: 392-400.

17. Lusardi P, Zoppi A, Preti P, Pesce RM, Piazza E, et al. (1999) Effects of insufficient sleep on blood pressure in hypertensive patients: a $24-\mathrm{h}$ study. Am J Hypertens 12: 63-68.

18. Broman JE, Lundh LG, Hetta J (1996) Insufficient sleep in the general population. Neurophysiol Clin 26: 30-39.

19. Liu Y, Tanaka H; Fukuoka Heart Study Group (2002) Overtime work, insufficient sleep, and risk of non-fatal acute myocardial infarction in Japanese men. Occup Environ Med 59: 447-451.

20. Nedeltcheva AV, Kilkus JM, Imperial J, Schoeller DA, Penev PD (2010) Insufficient sleep undermines dietary efforts to reduce adiposity. Ann Intern Med 153: 435-441.

21. Dahl RE (1999) The consequences of insufficient sleep for adolescents. Phi Delta Kappan 80: 354-359.

22. Roehrs T, Zorick F, Sicklesteel J, Wittig R, Roth T (1983). Excessive daytime sleepiness associated with insufficient sleep. Sleep 6: 319-325.
23. Naveed S, Qamar F, Abbas SS, Jawed SH, Raza W, et al. (2015) Appraisal of Techniques, Investigation and Analysis of Vitamin (B7) Biotin. Open Access Library Journal 2: e1894.

24. Naveed S, Qamar F, Abbas SS, Khalid SZM, Idrees J, et al. (2015) Rationality of Antibiotic Use A Survey Report. Journal of Biotechnology and Biosafety 3: 282-287.

25. Naveed S, Sana A, Rehman H, Qamar F, Abbas SS, et al. (2015) Prevalence and Consequences of PHOBIAS, Survey Based Study in Karachi. J Bioequiv Availab 7: 140-143.

26. Naveed S, Farooq S, Abbas SS, Jawed SH, Qamar F, et al. (2015) Contemporary Trends in Novel Ophthalmic Drug Delivery System: An Overview. Open Access Library Journal 2: e1497.

27. Qamar F (2015) Manifestation of zinc deficit in karachi pakistan; a cross sectional study. International Educational Scientific Research Journal 1: 16-18.

28. Sarah AS (2015) Dyslexia-a learning disorder; accountability of academicians. International Educational Scientific Research Journal 1: 1-2.

29. Sarah AS (2015) Enlightenment on naegleria fowleri; a brain eating amoeba-an alarming call. International Education and Research Journal 1: 1-3. 